\title{
DIAGNÓSTICO AMBIENTAL E DE PROCESSO DA LAVRA DE ROCHA ORNAMENTAL COM VISTAS A APLICAÇÃO DE TÉCNICAS DE PRODUÇÃO MAIS LIMPA
}

\author{
L.B. BAIMA ${ }^{1}$, J.C. PONTES ${ }^{2}$ \\ Instituto Federal de Educação, Ciência e Tecnologia do Rio Grande de Norte \\ leonelbaima@gmail.com ${ }^{1}$ \\ julio.pontes@ifrn.edu.br ${ }^{2}$
}

Artigo submetido em 25/11/2019 e aceito em 11/12/2019

DOI: $10.15628 /$ holos.2019.9202

\section{RESUMO}

A gestão de resíduos sólidos no setor de rochas ornamentais é de grande importância, tendo em vista a enorme quantidade de resíduos gerados no processo, que em média atingem a faixa de 65 a 75\%. Além de representar perdas na produção, os rejeitos afetam o meio ambiente e há desperdício dos recursos minerais, causando um grande impacto socioambiental. Uma vez que os rejeitos são depositados e estocados de forma inadequada, prejudica a própria sequência dos trabalhos de extração e além disso criando riscos de acidentes. A respeito da metodologia, implementou-se um estudo de caso realizado em uma pedreira de rocha ornamental localizada no Sítio Mufumbo, município de Parelhas-RN, inicialmente foi feito um levantamento bibliográfico em
\end{abstract}

artigos científicos, periódicos, anais de congressos, livros, teses, dissertações, leis, normas e manuais sobre os temas aqui expostos. Constatou-se que os processos associados à atividade econômica da mineração são responsáveis pela geração de resíduos sólidos, emissões atmosféricas e efluentes líquidas, ocasionando comprometimento ambiental, o qual pode ser, por vezes, irreparável. No presente caso, tem-se que a extração de rochas ornamentais é um procedimento gerador de vultuosos volumes de rejeitos, de maneira que deve ser promovido o seu aproveitamento através do emprego em materiais que podem ser utilizados e comercializados.

PALAVRAS-CHAVE: Diagnóstico Ambiental, Rochas Ornamentais, Sustentabilidade.

\section{ENVIRONMENTAL AND PROCESSING DIAGNOSIS OF THE ORNAMENTAL ROCK LAVAGE WITH A VIEW TO THE APPLICATION OF CLEANER PRODUCTION TECHNIQUES}

\begin{abstract}
Solid waste management in the ornamental rock sector is of great importance given the enormous amount of waste generated in the process, which on average reaches the range of 65 to $75 \%$. In addition to representing losses in production, tailings affect the environment and the waste of mineral resources, causing a great socio-environmental impact. Since the tailings are deposited and stored improperly, it damages the very sequence of the extraction work and also creates risks of accidents. Regarding the methodology, a case study was carried out in an ornamental rock quarry located in the Mufumbo site, in the city of Parelhas, RN.
\end{abstract}

Initially a bibliographic survey was carried out in scientific articles, periodicals, annals of congresses, books, theses, dissertations, laws, standards, and manuals on the topics discussed here. It was found that the processes associated to the economic activity of the mining are responsible for the generation of solid, liquid and gaseous wastes, causing environmental compromise, which can sometimes be irreparable. In the present case, the extraction of ornamental rocks is a procedure that generates large volumes of solid waste, so that its use must be promoted through the use of materials that can be used and marketed.

KEYWORDS: Environmental diagnosis. Ornamental rocks. Sustainability. 


\section{INTRODUÇÃO}

A indústria da mineração representa uma atividade ambientalmente agressiva, uma vez que envolve desmatamentos, degradação de habitats e alterações na geomorfologia e biodiversidade local. Por outro lado, o progresso técnico e econômico impulsiona esta atividade em busca de matérias-primas básicas para a manutenção do estilo de vida da sociedade moderna (LEITE; JÚNIOR; FABRI, 2012).

A rocha ornamental é definida pela Associação Brasileira de Normas Técnicas na NBR 15012:2013, como um material rochoso natural, submetido a diferentes graus ou tipos de beneficiamento, utilizado exercendo uma função estética. A rocha para revestimento corresponde à rocha natural que, submetida a processos diversos de beneficiamento, é utilizada no acabamento de superfícies, especialmente pisos, paredes e fachadas, em obras de construção civil.

O setor de rocha ornamental se destaca na economia brasileira com importante parcela na pauta de exportações, somando US\$ 1.107,1 milhões e 2,36 milhões toneladas em 2017, os três principais destinos foram EUA, China e Itália. O Rio Grande do Norte figura na atualidade como o $5^{\circ}$ maior exportador de rocha ornamental do Brasil (ABIROCHAS, 2018).

A gestão de resíduos sólidos no setor de rochas ornamentais é de grande importância, tendo em vista a enorme quantidade de resíduos gerados no processo, que em média atingem a faixa de 65 a 75\%. Além de representar perdas na produção, os rejeitos afetam o meio ambiente e há desperdício dos recursos minerais, causando um grande impacto socioambiental. Uma vez que os rejeitos são depositados e estocados de forma inadequada, prejudica a própria sequência dos trabalhos de extração e além disso criando riscos de acidentes (CAMPOS, 2009).

Técnicas de Gestão ambiental como a Produção mais Limpa $(\mathrm{P}+\mathrm{L})$ podem ser aplicadas a atividade de lavra a fim de minimizar os impactos ambientais causados ao meio ambiente, reduzir o uso predatório dos recursos naturais e cumprir com os requisitos legais previstos no licenciamento ambiental, assegurando ganhos nas esferas social, econômica e ambiental, corroborando para a sustentabilidade local e competitividade da empresa.

De acordo com a United Nations Environmental Program/United Nations Industrial Development Organization - UNEP/UNIDO, a Produção mais Limpa é a aplicação contínua de uma estratégia ambiental preventiva e integrada, nos processos produtivos, nos produtos e nos serviços, para reduzir os riscos relevantes aos seres humanos e ao meio ambiente. Em outras palavras, seriam os ajustes no processo produtivo que permitem a redução da emissão/geração de resíduos, podendo ser realizadas desde pequenas reparações no modelo existente até a aquisição de novas tecnologias (simples e/ou complexas).

Este artigo objetiva realizar um diagnóstico ambiental e de processo da atividade de lavra de rocha ornamental no Sítio Mufumbo em Parelhas-RN, fornecendo o embasamento necessário para se dar os primeiros passos rumo a implementação do programa de $\mathrm{P}+\mathrm{L}$. 


\section{METODOLOGIA}

O estudo de caso foi realizado com base na metodologia de implementação de técnicas de $\mathrm{P}+\mathrm{L}$ recomendada pela UNEP (2004) e pelo CNTL (SERVIÇO NACIONAL DE APRENDIZAGEM INDUSTRIAL, 2003a).

Para se adequar ao objetivo proposto neste trabalho e a realidade da empresa estudada, no contexto deste estudo, utilizou-se as etapas de planejamento e organização (1) e de préavaliação (2) e seus passos, quais sejam: obter comprometimento gerencial, identificar barreiras e soluções, estabelecer a abrangência da $\mathrm{P}+\mathrm{L}$, organizar ecotime, desenvolver fluxograma de processo e realizar diagnóstico ambiental e de processo como pode ser observado na Figura 1.

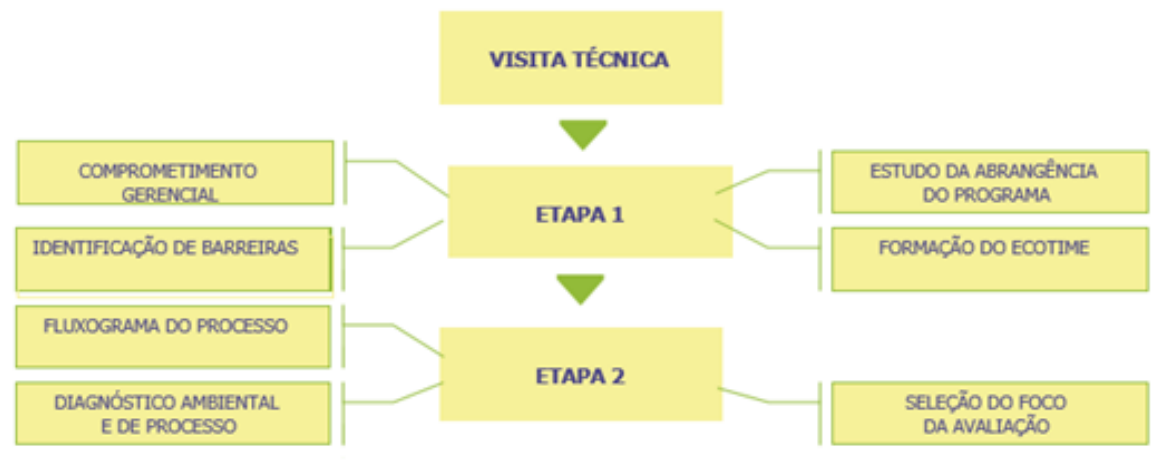

Figura 01: Passos para implementação de um programa de $P+L$.

\section{DIAGNOSTICO AMBIENTAL}

\subsection{Localização da área de estudo}

O município de Parelhas situa-se na mesorregião Central Potiguar e na microrregião Seridó Oriental, limitando-se com os municípios de Carnaúba dos Dantas, Equador, Jardim do Seridó e Santana do Seridó e com o Estado da Paraíba, abrangendo uma área de $523 \mathrm{~km}^{2}$, inseridos na folha Jardim do Seridó (SB.24-Z-B-V), na escala 1:100.000, editada pela SUDENE.

A sede do município tem uma altitude média de $266 \mathrm{~m}$ e coordenadas $06^{\circ} 41^{\prime} 16,8^{\prime \prime}$ de latitude sul e $36^{\circ} 39^{\prime} 28,8^{\prime \prime}$ de longitude oeste, distando da capital cerca de $249 \mathrm{~km}$. A Figura 2 exibe o mapa de localização do município Parelhas, em destaque a poligonal da área de estudo, que corresponde aos limites de lavra da pedreira, autorizado pelo Departamento Nacional de Produção Mineral (DNPM). 


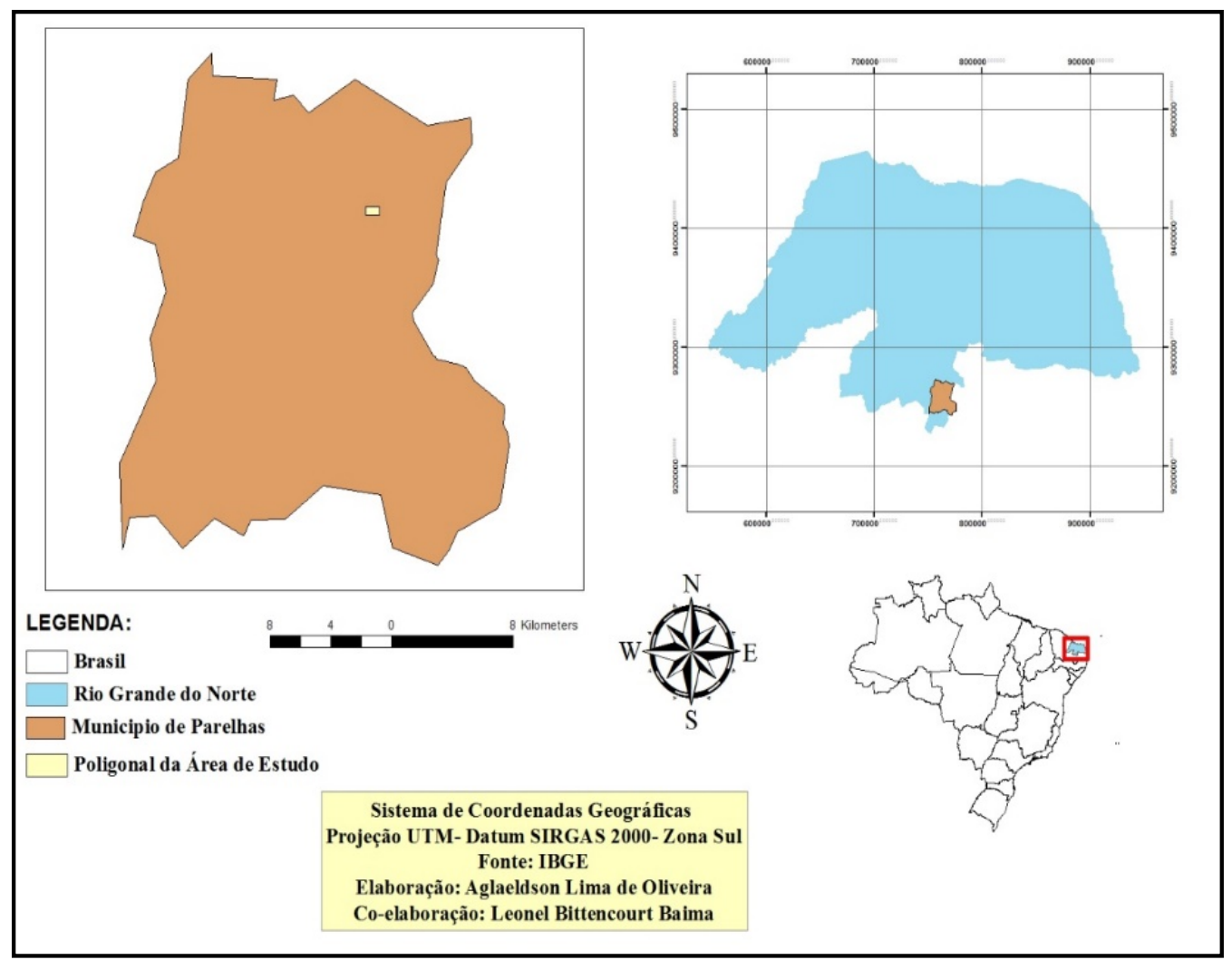

Figura 2 - Mapa de localização do município de Parelhas-RN.

O acesso ao local se faz a partir de Natal-RN, através da BR-427, no sentido oeste do estado, na direção da sede do município de Jardim do Seridó, onde se percorre $208 \mathrm{~km}$, passando pelas sedes dos Municípios de Santa Cruz, Currais Novos e Acari-RN, até o entroncamento com $\mathrm{RN}-221$. A partir deste entroncamento e por esta segunda rodovia serão percorridos, mais $20 \mathrm{~km}$, até a sede do município de Parelhas-RN.

Para o acesso ao Sítio Mufumbo, localizado na zona rural de Parelhas, toma-se uma estrada carroçável, no sentido Nordeste, na direção de Nova Palmeira-PB, passando pela Fazenda Carnaubinha, que distam aproximadamente, $15 \mathrm{~km}$ e mais $4 \mathrm{~km}$, na direção Leste até o local da área objeto do estudo.

O percurso acima descrito totaliza $247 \mathrm{~km}$, sendo $228 \mathrm{~km}$ feitos por estradas pavimentadas e $19 \mathrm{~km}$ por uma estrada carroçável, transitável durante qualquer período do ano.

\subsection{Geomorfologia}

De acordo com Mascarenhas et. al. (2005), o relevo predominante do município de Parelhas é ondulado e montanhoso formado por longos cordões de 45 serras e serrotes, com direção preferencial NNE-SSW, que ocorrem principalmente nas partes leste, nordeste, sul e sudeste da cidade. A outra parte do município apresenta um conjunto geomorfológico plano, suave e ondulado, principalmente nas áreas ao longo das margens do Rio Seridó.

O aspecto genético e a evolução das formas de relevo ora apresentada evidenciam no contexto regional, fenômenos a variações paleoclimáticas. 
O intemperismo físico-químico, que atuou sobre as estruturas tectônicas pré-existentes e sobre os diferentes litotipos, com diversidade de competência das rochas e estruturas reagiram de forma diferenciada estabelecendo a erosão diferencial. As estruturas regionais com formas suaves, ondulados, com vales em $U$, rios com meandros e erosão horizontal, significando, portanto, que o relevo atingiu a sua maturidade, segundo a classificação de Davis.

Ao sul da área da lavra, as estruturas regionais tendem a planares diminuindo a altitude, na direção do entalhamento do Rio Seridó, com cotas médias variando de 300 a 400 metros. Os cursos d'água também desempenharam um papel fundamental na modelação da morfologia regional atuando nos processos de erosão, transporte de sólidos e deposição dos sedimentos.

No município de Parelhas, a mineração é sustentável há vários anos; todavia, os dados concernentes à referida atividade econômica manifestam-se isoladamente, em diminutas escalas, implicando em dificuldades para lidar-se adequadamente com o que diz respeito ao meio ambiente e à mineração.

Neste sentido, faz-se necessário produzir informações básicas alusivas ao subsídio de informações voltadas para o potencial econômico das jazidas, o beneficiamento (conforme o jazimento) e os métodos de lavra.

Com o caráter de informações auxiliares, tem-se que a rocha clorita-xisto é predominante, abrangendo $85 \%$ da área integral do município, havendo associação direta às superfícies aguçadas e convexas dissecadas (NASCIMENTO, 2014).

Os processos de pedogênese ocorrentes na rocha, assim como os morfogenéticos, propiciaram os neossolos regolíticos e litóicos, com composição de $92 \%$ da área do estudo implementado por Nascimento (2014).

\subsection{Solos}

Os solos da localidade segundo MASCARENHAS et. al. (2005), estão relacionados às rochas Pré-cambrianas para os solos litólicos e Quartenário para os depósitos aluvionais. Os solos litólicoseutróficos se caracterizam por serem rasos, com textura pouco arenosa e bastante pedregosa. São originados de rochas gnáissicas, graníticas, xistos e presentes nas áreas, onde o relevo é ondulado e montanhoso. Estes solos apresentam baixos rendimentos nas atividades agrícolas e são explorados apenas para as atividades de pastoreios.

Os solos aluvionais são poucos representativos em termos de extensão, ocorrem nas partes planas das bacias de inundações, nos diversos riachos e seus afluentes da região e se caracterizam por apresentarem estruturas arenosas e argilosas.

Os solos líticos eutróficos predominam na região, sendo caracterizados por elevada fertilidade natural, textura arenosa e média, apresentado fase pedregosa e rochosa, com um relevo suave ondulado, ondulado, forte ondulado e com presença de montanhas. Praticamente, não ocorre o cultivo do solo, aproveitando-se a vegetação natural na pecuária extensiva, não havendo destinação à agricultura devido às restrições oriundas da escassez de recursos hídricos, assim como a carência da utilização de implementos agrícolas, devido a reduzida espessura, rochosidade e pedregosidade, de forma que é necessário preservar a vegetação natural para que ocorra a proteção da fauna e da flora (BRASIL, 2014). 
A respeito das características propícias para a agricultura, tem-se que a aptidão regular restringe-se ao pasto, de forma que nas áreas sudoeste e leste, há indicação para preservação da fauna e da flora. Considerando-se o sistema de manejo, tem-se que este é pautado por baixo e médio nível tecnológico, de forma que as práticas agrícolas encontram-se condicionadas à tração animal e ao trabalho braçal, utilizando-se mecanismos agrícolas elementares (BRASIL, 2014).

\subsection{Recursos Hídricos}

Este item aborda aspectos do fluxo hídrico superficial e algumas características hidrogeológicas da região levando-se em conta a dinâmica regional e suas características geológicas, bem como, fornece dados referentes à qualidade da água. (MASCARENHAS et. al., 2005).

A drenagem é constituída por pequenos riachos intermitentes, de modo que os vales apresentam-se secos durante pelo menos oito meses em cada ano. A rede hidrográfica é formada pelos Riachos das Pinturas, dos Bois e da Carnaubinha, que alimentam o Rio Seridó, que faz parte integrante do Rio Piranhas.

Em linhas gerais, os cursos hídricos da região Seridó acompanham o alinhamento estrutural dos pequenos e grandes fraturamentos regionais. Os riachos que abrangem as áreas do projeto se encaixam diretamente sobre estes alinhamentos estruturais, com vales variando de pouco a muito profundos, formando drenagens de média a alta velocidade de escoamento, com constantes quebras de direção.

$\mathrm{Na}$ área objeto de estudo, a drenagem adquire um porte menos denso e assume um padrão dentrítico e sem nenhum controle estrutural. Predominam os sulcamentos dos relevos com feições onduladas, onde os pontos de máximas depressões coincidem com os leitos das drenagens.

A oferta de recursos hídricos, tanto em quantidade como em qualidade, é um dos principais fatores limitantes ao desenvolvimento das cidades, visto que esta demanda uma atividade contínua e não pode ficar sujeito às variações das distribuições de chuva, de forma que é necessário haver um manancial de água para suprir as demandas em períodos de estiagem.

Tais características da região semiárida tem levado a tomada de decisões, por parte dos órgãos governamentais visando a segurança hídrica adequada durante os períodos de seca, pela construção de reservatórios para fornecimento de água para indústria, agricultura e abastecimento público (MOLLE, 1994).

É correto afirmar que os reservatórios são ecossistemas aquáticos artificiais formados a partir do barramento de um rio em uma bacia hidrográfica, possuindo características que remetem para sistemas lóticos, referente à águas continentais em movimento, ou lênticos, que são sistemas com águas paradas (CONAMA, 2005), de acordo com seu tempo de residência. Os concernidos sistemas promovem uma continua e dinâmica ligação entre ecossistemas terrestres e aquáticos e por isso são sensíveis às intervenções artificiais na bacia de drenagem. A construção de reservatórios para diversos fins é uma das grandes experiências humanas na modificação dos ecossistemas naturais (STRASKRABA E TUNDISI, 1999). 
Contudo, observa-se que a segurança hídrica adequada através da garantia de elevada quantidade de água armazenada nos reservatórios nem sempre é uma condição de disponibilidade adequada, visto que alguns fatores climáticos da região podem alterar em grande escala a qualidade da água armazenada.

As extensas cadeias de reservatórios existentes nas bacias do Brasil são de extrema expressão social, ecológica, econômica e hidrológica, haja vista que os referidos sistemas foram utilizados como base para o desenvolvimento regional, uma vez que são destinados para diversas finalidades, como hidroeletricidade, irrigação, piscicultura, transporte, controle de cheias, recreação, turismo e reserva de água para o abastecimento humano (POOLMAN, 2006).

\subsection{Clima}

A fisiografia da região do Seridó está inserida no semiárido nordestino, onde o clima apresenta características adversas, com temperaturas elevadas e estações chuvosas curtas e irregulares. (MASCARENHAS et. al., 2005).

A hidrologia da região semiárida é caracterizada por bacias hidrográficas, de rios intermitentes ou perenizados, caracterizados por um regime climático, onde as precipitações pluviais são escassas e mal distribuídas e uma alta taxa de evaporação determinada por um balanço energético positivo com grande incidência de radiação solar devido a um céu claro, com intensa insolação, implicando em temperaturas elevadas.

Há um déficit hídrico na região semiárida, a qual apresenta marcante diferença entre o período chuvoso, com precipitações concentradas em 3 a 4 meses do ano, e o período seco prolongado com taxas de evaporação potencial normalmente superando os $2000 \mathrm{~mm} / \mathrm{ano}$.

Na porção semiárida do estado do Rio Grande do Norte, a microrregião do Seridó é uma das áreas do planeta enquadrada pela Convenção de Combate à Desertificação (CCD) como núcleo de desertificação, devido ao fato de expressar baixos índices de umidade do solo, fato decorrente da alta evapotranspiração, vinculado à baixa ocorrência de chuvas. Tais regiões são bastante susceptíveis aos processos de desertificação relacionados com a ação da variação climática e com as atividades antrópicas

Em tais circunstâncias, nas quais os eventos pluviais ocorrem em baixas médias e com irregularidade em sua constância, a grande preocupação deve ser com as demandas, que necessitam ser monitoradas para uma possibilidade mais adequada de gestão das águas. Perante este fator, a evapotranspiração, que retira da superfície terrestre aproximadamente $59 \%$ do volume precipitado, figura como uma variável indispensável no monitoramento dos recursos hídricos e no desenvolvimento de pesquisas que almejem à formulação de modelos que gerem sua estimativa de forma eficaz, eficiente e precisa.

A construção de barragens implica na produção de reservatórios, concebendo uma solução para o problema, visto que a água das chuvas é armazenada para uma utilização a posteriori. Contudo, com o decurso temporal, constatou-se que a solução para a falta de água não é apenas o armazenamento, mas é necessário que os recursos hídricos sejam de alta 
qualidade, demandando controle técnico dos reservatórios, visando impedir a contaminação da água.

A qualidade dos recursos hídricos é comprometida nos reservatórios devido a exploração dos recursos da água e do solo, de forma que a redução da qualidade hídrica está relacionada com a má conservação do solo e com o uso irracional dos recursos naturais (FRANCO, 2008). A agricultura, a criação de rebanhos e a atividade industrial próxima aos reservatórios revertem na alteração da qualidade da água represada, impedindo seu uso para as finalidades originais (CEBALLOS et al., 1997).

\subsection{Flora e Fauna}

A quase totalidade da região encontra-se recoberta pela vegetação de caatinga, ambiente caracterizado pelas temperaturas elevadas, umidades relativas médias e precipitações pluviométricas médias anuais baixas. Segundo MASCARENHAS et. al. (2005), há a existência de caatinga hiperxerófila que corresponde à vegetação de caráter mais seco, com abundância de cactáceas e plantas de porte mais baixo e espalhadas.

Tais características climáticas, particulares da região semiárida, induzem ao estabelecimento de algumas feições, como a formação vegetal da região composta pela caatinga hiperxerófila, que são plantas resistentes à seca e solos de relevo plano com baixa profundidade e susceptíveis à erosão natural, com pouca ou nenhuma formação de aquíferos (SILVA; ARAÚJO, 2003).

Especificamente na área em volta da frente de lavra foi observada grande abundância de cactáceas, leguminosas e bromeliáceas. As espécies que se destacam são: Pereiro, Favela, Facheiro, Mufumbo, Marmeleiro, Xiquexique, Coroa-de-frade, Macambira, Unha-de-gato, Angico, Jurema branca, Juazeiro, Catingueira entre outras.

As alterações antrópicas que este ecossistema vem sofrendo nos últimos anos, principalmente com desmatamento através de queimadas para a implantação de atividades agrícolas, pastoreio e retirada de madeiras, remoção de solo, acarretam a destruição de habitats, consequentemente diminuindo as populações faunísticas, sobretudo dos animais de maior porte.

A Ornitofauna local encontra-se representada principalmente pela rolinha, tetéu, sibite, anum preto, anum branco, carcará, galo de campina, golinha, concriz, cancão, papa-capim, azulão, canário, sabiá, casaca de couro, arribaçã, seriema, lambu, lavadeira, gavião, entre outros.

Da Herpetofauna existente na região os mais conhecidos são o calango, camaleão, tejo e as cobras coral, cascavel, jararaca, corre-campo, cobra-verde, jiboia dentre outras. Dentre os anfíbios, destacam-se o sapo cururu, perereca arborícola. Enquanto os mamíferos são representados principalmente pelo preá, tatu-verdadeiro, tatu-peba, gato-do-mato, mocó, gambá, raposa, dentre outros.

Esta caracterização ambiental é de suma importância uma vez que fornece embasamento que permite inferir os aspectos e impactos ambientais a que este frágil ecossistema de caatinga está sujeito. 


\section{DIAGNÓSTICO DE PROCESSO}

Como toda atividade do ramo da mineração, a extração dos blocos de uma lavra de rochas ornamentais é uma atividade que causa um alto impacto ambiental. Destaca-se que tais impactos podem repercutir em danos ao meio ambiente e/ou agravos à população circunvizinha e aos funcionários da empresa.

Para se dar o início ao processo de extração do recurso natural, primeiramente, faz-se necessário o desmatamento e a remoção do solo para tornar viável o acesso e a operação da lavra, o que provoca um efeito negativo na fauna e flora, além do impacto visual. Foi constatado em campo através de visita in loco, um intenso movimento de máquinas pesadas, carros e caminhões consequentemente gerando diversos impactos ambientais como ruídos e emissões atmosféricas.

Para a operacionalização da lavra, há uma intervenção significativa no ambiente, com desmatamento e decapeamento do estéril, limpeza e terraplanagem das áreas de servidão, construções de acessos, área de estocagem e transporte de blocos, pátio de manobra, área de depósito de rejeitos, conforme pode ser observado mostrado na Figura 4, onde 1= corte primário para desabamento de fatias maiores, $2=$ esquartejamento em corte secundário, $3=$ vias de transporte dos blocos, 4= desmatamento, decapeamento de estéril e 5= Máquina de corte a fio diamantado, (OLIVEIRA 2006).

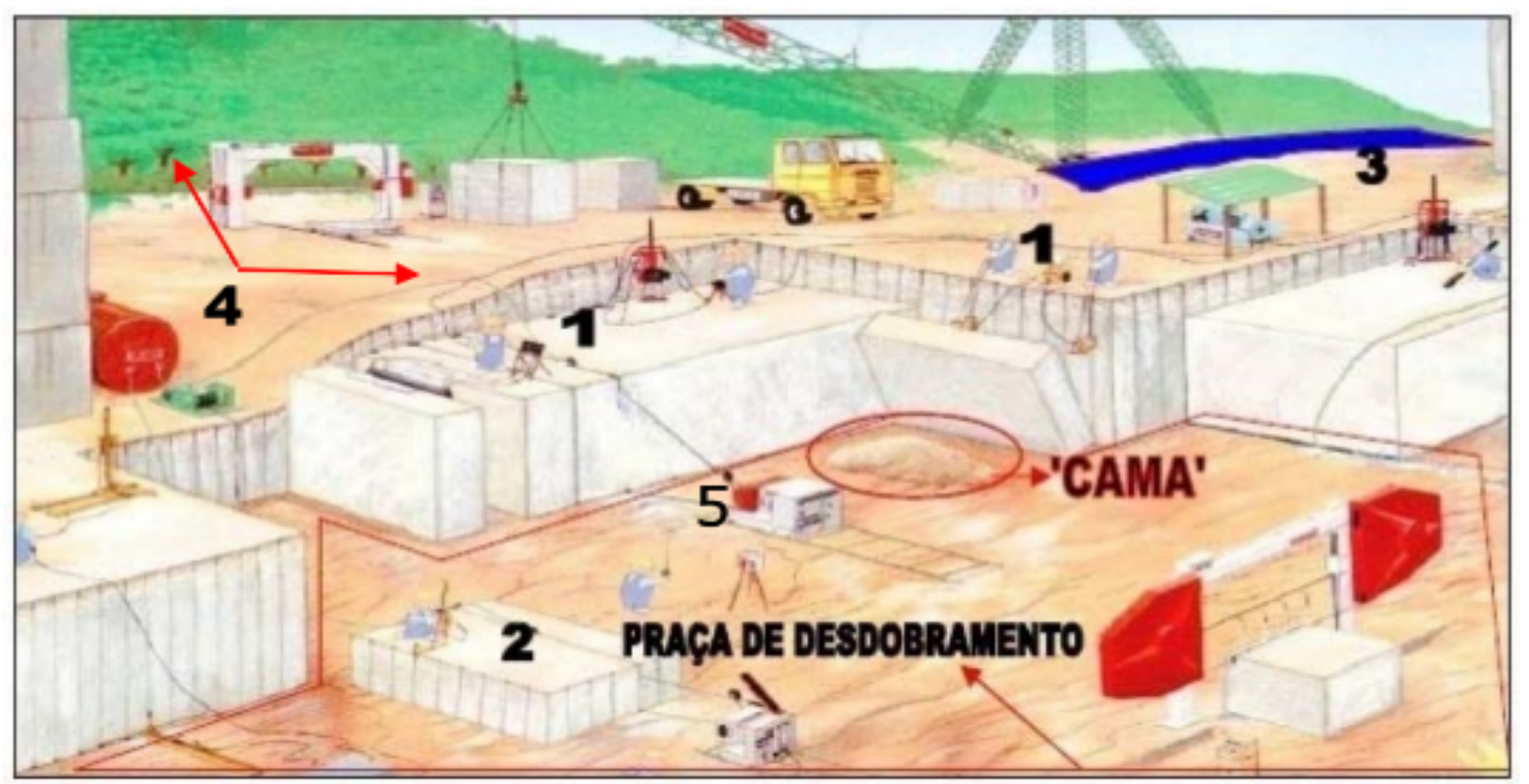

Figura 4 - Ilustração de uma frente de lavra de rocha ornamental, em maciço, utilizando fio diamantado.

O desmonte de rochas consiste na separação de blocos primários o qual denomina-se prancha. Uma vez terminada a separação do bloco primário procede-se o corte em fatias e, posteriormente, a extração de blocos secundários, através da operação de esquadrejamento.

Os blocos assim produzidos apresentarão dimensões e formas variadas e irregulares, onde se faz necessário realizar uma operação de acabamento, com vista à posterior comercialização. 
O desmonte termina com o transporte do bloco para o pátio de estocagem, a limpeza da frente de lavra e a retirada das partes remanescentes do bloco primário para a área destinada à deposição dos rejeitos (bota-foras), conforme pode ser observado na Figura 5.

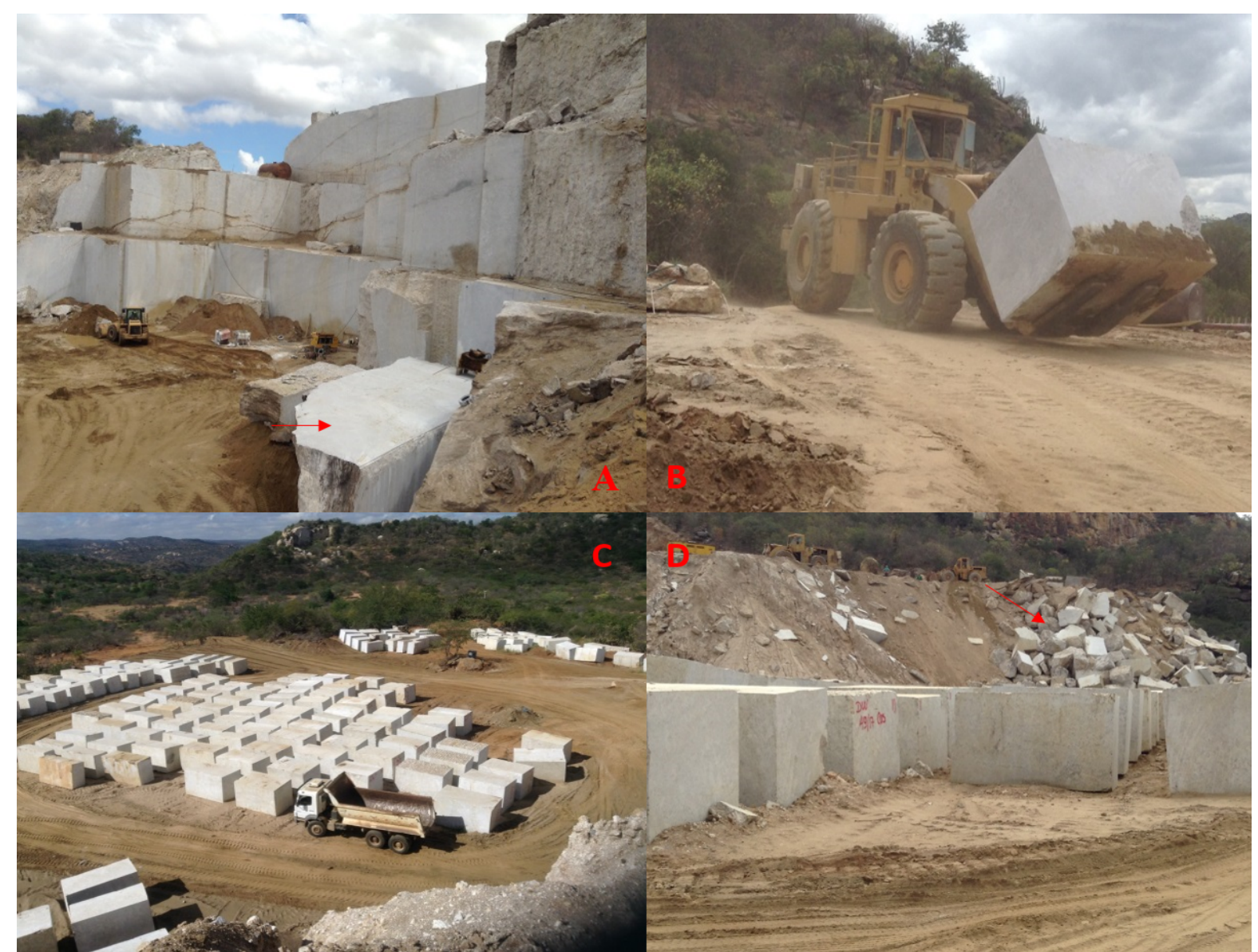

Figura 5: Desmonte - $\mathrm{A}=$ Prancha tombada; $\mathrm{B}=$ Transporte do bloco para o pátio de estocagem; $\mathrm{C}=$ Pátio de estocagem, $D$ = Deposição de rejeitos.

A pedreira no Sitio Mufumbo emprega 40 funcionários e gera cerca 80 empregos indiretos na região, possui licença ambiental do órgão fiscalizador competente IDEMA, a empresa funciona $24 \mathrm{~h}$ por dia em dois turnos de $12 \mathrm{~h}$. dispõem de alojamento para os funcionários com cozinha, refeitório, área para descanso e convivência.

O produto final da pedreira é o bloco com 3 metros de comprimento por 1,90m de altura e largura respectivamente. No sitio são extraídas duas variedades de rocha ornamental do tipo granito branco, comercializadas sobe a denominação Cristal White e o Dália White, este segundo destaca-se pela superior qualidade estética e valor de mercado.

Os blocos da lavra são destinados a unidade beneficiadora que fica localizada no município de Campina Grande - PB, onde serão desdobrados em chapas polidas que são o produto final da empresa. As rochas são exportadas principalmente para a Itália e para o estado brasileiro Espirito Santo, já o rejeito do granito fica acumulado no pátio da empresa na forma de pilhas de rejeitos.

Este artigo buscou através de análises laboratoriais (ver anexo) caracterizar estes rejeitos afim de sugerir possíveis usos como alternativa a reciclagem deste material. 
O consumo de água em média é 10.000 litros por dia na empresa representando 25 caminhões pipa de 12.000 litros, adquiridos ao custo de $\mathrm{R} \$ 120,00$ cada, a água é oriunda do açude Boqueirão localizado próximo a pedreira.

As máquinas envolvidas na operação de lavra assim como os veículos, tratores e caminhões não possuem um estacionamento delimitado, foi observado manchas de óleo no solo na área de extração, o que configura um impacto ambiental no solo. Como medida mitigadora foi sugerido a criação de um estacionamento com piso impermeável.

$\mathrm{Na}$ Etapa de desmonte das rochas, é comum o uso de explosivos tipo granulado com espoleta e ou cordel detonante apenas para preparação do acesso as frentes de lavra, mas nunca no maciço, para que se evite fraturas.

Foi constatado durante a pesquisa de campo, grande quantidade de material particulado em virtude da movimentação de máquinas pesadas, assim como excesso de ruído. Embora a legislação obrigue as empresas a fornecerem os equipamentos de proteção individual, como protetor auricular e mascaras, nota-se uma certa resistência por parte dos funcionários em utilizá-los corretamente.

Não existe nenhuma comunidade no entorno da pedreira, portanto é inexistente o impacto a vizinhança, porém, os trabalhadores estão expostos aos riscos de acidente de trabalho e a insalubridade.

A empresa emprega 40 funcionários e gera mais 80 empregos indiretos, injetando recursos na econômica local e contribuindo há 4 anos para o desenvolvimento da região o que figura como impacto ambiental positivo.

Com o decurso dos anos, foi possível observar a intensificação do consumo dos recursos naturais, de forma que a mineração de rochas ornamentais é responsável por consumir uma significativa parcela destes recursos, com vistas à produção de chapas polidas para emprego nas obras de construção civil. Tal atividade implica em uma ampla produção de resíduos, os quais são capazes de impactar negativamente o meio ambiente.

Segundo a Resolução $n^{\circ}$ 307/2002, do Conama (BRASIL, 2002) e da lei no 12.305/2010 (BRASIL, 2010) leva a responsabilidade pelo gerenciamento dos concernidos recursos ao empreendedor. Visando-se a promover o apontamento de eventuais falhas na referida gestão e com o objetivo de possibilitar a redução da geração dos mencionados resíduos, através do presente estudo de caso, foi possível verificar que na integralidade das fases dos procedimentos de lavra, dá-se a geração dos resíduos, com ênfase para os fragmentos das rochas que são considerados como perdas.

Conforme o diagnóstico de processo desenvolvido nesta pesquisa foi constatado a geração de resíduos sólidos associados a atividade de lavra, onde há a predominância da geração de resíduos no decapeamento de limpeza, seguido pela atividade de corte e, em seguida, o tombamento de pranchas. Verificou-se que a menor geração de resíduos se deu na perfuração. Constatou-se que a redução da aplicação de recursos hídricos pode se dar com a implementação de formas eficazes no corte das rochas, havendo uma redução no consumo relativo, intensificando-se o rendimento do maciço rochoso. 


\section{CONCLUSÃO}

O estudo do diagnóstico ambiental e do processo promoveu os dados constantes na presente pesquisa. Observou-se que há carência de estudos que almejem a implementação de uma Produção Mais Limpa na lavra das rochas ornamentais, de forma que os estudos constatam que a predominância das soluções apresentadas pelos pesquisadores encontra-se associadas à reciclagem dos resíduos. Assim sendo, a redução da produção de resíduos na lavra tem potencial de implicar na aplicação de práticas sustentáveis, com o objetivo de promover a racionalidade e economia dos recursos naturais, com ênfase para os recursos em si, assim como em relação aos recursos hídricos e o consumo de combustíveis.

O município em questão é destaque na extração de rochas ornamentais; todavia, há a demanda da associação da referida atividade à observância de técnicas de proteção ao meio ambiente.

Com o escopo de apresentar resolução à produção de resíduos de natureza sólida na lavra de rochas ornamentais, o diagnóstico obtido pela presente pesquisa apresenta imprescindível relevância, com o intuito de apontar as possibilidades de atenuar a geração dos resíduos, com pauta na sustentabilidade, promovendo-se a conservação dos recursos naturais para as gerações vindouras. O desenvolvimento de técnicas de Produção Mais Limpa é uma forma de materializarse a preservação dos recursos minerais, redução das emissões e proporcionar a diminuição do emprego de recursos de natureza financeira para a empresa, considerando-se que a possibilidade da redução da quantidade de interrupções para a manutenção corretiva.

Percebeu-se que os processos que associam-se à atividade econômica da mineração são responsáveis pela geração de resíduos sólidos, efluentes líquidos e emissões atmosféricas, ocasionando comprometimento ambiental, o qual pode ser, por vezes, irreparável. No presente caso, tem-se que a extração de rochas ornamentais é um procedimento gerador de vultuosos volumes de resíduos sólidos, de maneira que deve ser promovido o seu aproveitamento através do emprego em materiais que podem ser utilizados e comercializados, gerando renda na região, consistindo na reutilização residual para a fabricação de cerâmicas, pavimentação e argamassa, dentre outros itens, promovendo-se, desta maneira, um estágio completo de extração, produção e aproveitamento integral da carga residual.

No geral, sabe-se que grande parte dos processos que envolvem a mineração como atividade econômica, são fontes geradoras de resíduos na forma de gases, líquidos ou sólidos, causando enorme degradação ambiental, por outro lado esta atividade gera um importante impacto socioambiental positivo, pois cria empregos diretos e indiretos movimentando a economia local.

$\mathrm{Na}$ fase de lavra, existem alternativas que permitem um corte mais preciso da rocha, gerando menos resíduos e aumentando a produtividade da jazida, se faz necessário estudos geológicos para identificar o melhor método de avanço na frente de lavra afim de minimizar a quantidade de perdas. 
As recomposições do solo e da vegetação e a recuperação da área degradada são de fundamental importância, uma vez que a região de Parelhas sofre com o processo da desertificação.

O uso correto dos equipamentos de proteção individual deve ser reforçado pelos gestores da empresa, a fim de minimizar os riscos à saúde dos colaboradores, causados pelo ruído excessivo e pelo material particulado.

Os resíduos sólidos gerados na atividade podem ser reaproveitados dentro da própria empresa para fazer aterros, construção das vias de acesso e utilizado como cama para o tombamento de blocos.

Características específicas do resíduo de granito, como granulometria fina, composição química e a inexistência de grãos mistos entre os componentes básicos, favorecem seu aproveitamento e reciclagem na produção de materiais cerâmicos como tijolos, telhas, blocos de concreto, grés porcelanato dentre outros materiais, foi possível observar ainda a presença de óxidos de metais raros no rejeito o que possibilita um uso mais nobre para este resíduo, para isto se faz necessário o aprofundamento desta pesquisa em trabalhos futuros.

\section{REFERÊNCIAS BIBLIOGRÁFICAS}

ACSELRAD, Henri. Ambientalização das lutas sociais - o caso do movimento por justiça ambiental. Rev. Estudos Avançados. v. 24, n. 68. 2010.

ASSOCIAÇÃO BRASILEIRA DE NORMAS TÉCNICAS. NBR 15012. Rochas para revestimentos de edificações - Terminologia, 02/09/2013, ABNT/CEE-187 Rochas Ornamentais. Rio de Janeiro: ABNT, 2003. 23p.

ASSOCIAÇÃO BRASILEIRA DA INDÚSTRIA DE ROCHAS ORNAMENTAIS - ABIROCHAS, Balanço das Exportações e Importações Brasileiras de Rochas Ornamentais em 2017, Informe 01/2018, Disponível em http://www.abirochas.com.br/Informe-01-2018.pdf acesso 21/03/2018.

BEZERRA, Francisco Diniz. Rochas ornamentais: novas perspectivas de desenvolvimento. Caderno Setorial ETENE. BNB. a.2. n.21. Dez. 2017.

BRASIL. Cadastro de fontes de abastecimento por água subterrânea - município de Parelhas. Brasília. 2014.

BRASIL. MINISTÉRIO DO TRABALHO. Relação Anual de Informações Sociais - RAIS. 2017a. Disponível em: <http://trabalho.gov.br>. Acesso: 29 abr. 2018. 
CAMPOS, A. R.; CASTRO, N. F.; VIDAL, F. W. H.; BORLINI, M. C. Tratamento e aproveitamento de resíduos de rochas ornamentais e de revestimento, visando mitigação de impacto ambiental. IN: Simpósio de Geologia do Nordeste, 23, 2009, Fortaleza,CE. Anais... Rio de Janeiro: CETEM/MCTI, 2009. p.16-25.

CANEPA, Carla. Cidades Sustentáveis: o município como lócus da sustentabilidade. São Paulo. Editora RCS, 2007.

COELHO, M. R.; VIDAL-TORRADO, P. Caracterização e gênese de perfis plínticos desenvolvidos de arenito do Grupo Bauru. I - Química. Rev. Bras. Ciênc. Solo vol.27 no.3 Viçosa May/June 2003.

COSTA, Thomaz C. e C. da. OLIVEIRA, Maria A. J. ACCIOLY, Luciano J. de O.; SILVA, Flávio H. B. B. Análise da degradação da caatinga no núcleo de desertificação do Seridó (RN/PB). Rev. bras. eng. agríc. ambient. vol.13 supl.0 Campina Grande Nov./Dec. 2009.

FABRI, E. S.; NALINI JÚNIOR, H. A.; LEITE, M. G. P. Explotação de rochas ornamentais e meio ambiente. 190 Desenvolvimento e Meio Ambiente, v. 26, p. 189-197, jul./dez. 2012.

FRANCO, T.; DRUCK, G. Padrões de industrialização, riscos e meio ambiente. Scientificelectronic library online, v. 3, n. 2, p. 61-72, 1998.

GANEM, Márcia. Casos de sucesso. Revista Sebrae. São Paulo. 2010.

IPIRANGA, Ana S. R. Desenvolvimento sustentável. RAM, Rev. Adm. Mackenzie (Online) vol.12 no.3. São Paulo. Jun, 2011.

MASCARENHAS. J. C. et. al. Projeto Cadastro de Fontes de Abastecimento por Água Subterrânea. Diagnóstico do Município de Parelhas, estado do Rio Grande do Norte. CPRM. Recife, PE. 2005.

MATTOS, Katty M. da C.; MATTOS, Karen M. da C. Valoração econômica do meio ambiente dentro do contexto do desenvolvimento sustentável. Revista Gestão Industrial. v.1. n.2. 2005.

MDIC. Balança. Rio Grande do Norte. 2017. Disponível em:

http://www.mdic.gov.br/balanca/comex-vis/uf/output/html/ap.html. Acesso em 05 jun 2018.

MOREIRA, J. C; JACOB, S. C et. al. Avaliação integrada do impacto do uso de agrotóxicos sobre a saúde humana em uma comunidade agrícola de Nova Friburgo, RJ. Revista Ciência Saúde Coletiva, vol. 7, no 2. São Paulo, 2009. 
NASCIMENTO, Paulo Sério de R. Fotomapeamento geológico, geomorfológico e pedológico do munlcípio de Parelhas-RN. Anais do Simpósio Regional de Geoprocessamento e Sensoriamento Remoto - GEONORDESTE 2014. Aracaju, Brasil, 18-21 novembro 2014.

REGADAS, I. C. M. C. Aspectos Relacionados às Lavras de Granitos Ornamentais com Fio Diamantado no Norte do Estado do Espírito Santo, Brasil. Tese de Mestrado. Escola de Engenharia de São Carlos da Universidade de São Paulo. USP. 128p. 2006.

SANTOS, Max M. A.; DESTEFANI, A. Z.; HOLANDA, J. N. F. Caracterização de resíduos de rochas ornamentais provenientes de diferentes processos de corte e beneficiamento. Matéria (Rio J.) vol.18 no.4 Rio de Janeiro Oct./Dec. 2013.

SATTERTHWAITE, David. Como as cidades podem contribuir para o Desenvolvimento Sustentável. In: MENEGAT, Rualdo e ALMEIDA, Gerson (org.). Desenvolvimento Sustentável e Gestão Ambiental nas Cidades, Estratégias a partir de Porto Alegre. Porto Alegre: UFRGS Editora, pp. 129-167, 2004.

SERVIÇO NACIONAL DE APRENDIZAGEM INDUSTRIAL DO RIO GRANDE DO SUL. Implementação de programas de produção mais limpa. Porto Alegre: CNTL, SERVIÇO NACIONAL DE APRENDIZAGEM INDUSTRIAL 2003a.

STELLIN JUNIOR, A., CARANASSIOS, A. Extração de rochas ornamentais. Brasil mineral, São Paulo, n.89, p.30-34, jun. 1991.

SOUZA, Christopher F.; CRUZ, Marcus Aurélio Soares; TUCCI, Carlos Eduardo Morelli. Desenvolvimento Urbano de Baixo Impacto: Planejamento e Tecnologias Verdes para a Sustentabilidade das Águas Urbanas. RBRH - Revista Brasileira de Recursos Hídricos Volume 17 n.2 - Abr/Jun 2012.

SKY. Tecnologia de perfuração jato de água. Pejaw. 2017. Disponível em: http://www.biotanol.eu/moagem/1756/tecnologia-de-perfura231227o-jato-de-agua.html. Acesso em 01 maio 2018.

UNEP. Understanding resource efficcient and cleaner production. Paris. 2004. 